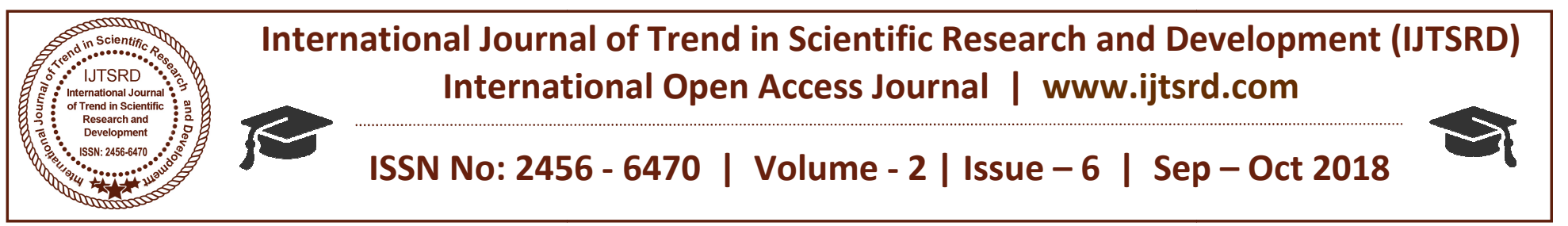

\title{
An Overview on Nano-Technology
}

\author{
A. C. Sountharraj ${ }^{1}$, P L. Subramanian ${ }^{2}$ \\ ${ }^{1}$ Assistant Professor, ${ }^{2}$ Student \\ Department of BCA \& MSC.SS, Sri Krishna Arts \& Science College, Kuniyamuthur, Coimbatore, India
}

\begin{abstract}
Nanotechnology ("nanotech") is used to exploit matter of a molecular, supramolecular and atomic scale. The earliest, widespread description of nanotechnology referred to the particular technological goal of precisely exploiting atoms and molecules for fabrication of macro-scale products, also now referred to as molecular nanotechnology.
\end{abstract}

Nanotechnology as defined by size is naturally very broad, including fields of science as assorted as surface science, organic chemistry, molecular biology, semiconductor physics, micro-fabrication, etc.

The associated research and applications are equally assorted, ranging from extensions of conventional device physics to completely new approaches based upon molecular self-assembly, from developing new materials with dimensions on the nanoscale to direct reign of matter on the atomic scale.

Keyword: nano-scale, atomic scale, nano-technology, molecular self-assembly, supramolecular.

\section{INTRODUCTION}

\section{Rise of Nano-Technology:}

The hypothesis that seeded nanotechnology were first discussed in 1959 by renowned physicist Richard Feynman in his talk There's Plenty of Room at the Bottom, in which he narrates the probability of synthesis via direct manipulation of atoms.

The term "nano-technology" was first used by Norio Taniguchi in 1974, though it was not widely known [1].

By Feynman's theory, K. Eric Drexler used the term "nanotechnology" in his 1986 book Engines of Creation: The Coming Era of Nanotechnology, which proposed the idea of a nanoscale "assembler" which would be able to create a facsimile of itself and of other items of whimsical complexity with atomic control [2].

In 1986, Drexler co-founded The Foresight Institute (with which he is no longer affiliated) to help increase public/cognizance and understanding of nanotechnology concepts and implications.

In the 1980s, two major breakthroughs sparked the growth of nanotechnology in modern aeon.

Initially, the invention of the scanning tunneling microscope in 1981 which equip unparalleled visualization of individual atoms and bonds, and was successfully used to manipulate individual atoms in 1989.

Binnig, Quate and Gerber also invented the analogous atomic force microscope that year [3].

Second, Fullerenes were discovered in 1985 by Harry Kroto, Richard Smalley, and Robert Curl, who simultaneously won the 1996 Nobel Prize in Chemistry. $\mathrm{C}_{60}$ was not at the outset by the name nanotechnology; the term was used concerning subsequent work with related graphene tubes (called carbon nanotubes and sometimes called Bucky tubes) which is a proposed potential applications for nanoscale electronics and devices.

\section{FUNDAMENTAL CONCEPT:}

Nanotechnology is the controller of functional systems at the molecular scale

$>$ One nanometer $(\mathrm{nm})$ is one billionth, or $10^{-9}$, of a meter [4].

$>$ By resemblance, typical carbon-carbon bond lengths, or the crevasse between these atoms in a 
molecule, are in the range $0.12-0.15 \mathrm{~nm}$, and a DNA double-helix has a diameter around $2 \mathrm{~nm}$.

$>$ On the other hand, the tiny cellular life-forms, the bacteria of the genus Mycoplasma, are around $200 \mathrm{~nm}$ in length

$>$ There are 25,400,000 nanometers in an inch

$>$ A sheet of newspaper is near 100,000 nanometers thick

$>$ On a comparison scale, if a marble were a nanometer, then one meter would be the size of the Earth

\section{INVETIGATION approaches:}

$>$ Nano material

$>$ Top down approches

$>$ Bottom up approches

\section{NANO MATERIALS:}

$>$ Interface and colloid science has given a better advancement to abundant materials which may be useful in nanotechnology, such as carbon nanotubes and other fullerenes, and sundry nanoparticles and nanorods. Nanomaterials with fast ion transport are also linked to nanoionics and nanoelectronics

$>$ Evolution of applications engulf semiconductor nanoparticles to be used in the succeeding generation of products, such as display technology, , solar cells and biological imaging,lighting; see quantum dots.

$>$ Recent implementation of nanomaterials consist of range of biomedical applications, such as tissue engineering, drug delivery, and biosensors.

\section{Zinc oxide:}

Dirt repellent, hydrophobic, cosmetics \& stain resistant.

\section{Silver ion:}

Healing property

\section{Aluminum silicate:}

Scratch resistance

\section{Gold ion:}

Chip fabrication, drug delivery.

\section{BOTTOM UP}

In the bottom up approach non identical materials and devices are formulated from molecular components of their own. They chemically assemble themselves by cognizing the molecules of their own breed.
Examples of molecular self assembly are Watson crick base pairing, nano-lithoghraphy [5].

\section{TOP DOWN}

In top down approach nano objects and materials are generated by huge entities without bouncing its atomic reactions usually top down approach is rehearse less as liken to the bottom up approach.

> Solid-state techniques can also be acquainted with creating devices known as nanoelectromechanical systems or NEMS, which are affiliated to microelctromechanical systems or MEMS.

$>$ MEMS became empirical once they could be fabricated using remold semiconductor device fabrication technologies, normally used to urge electronics.

\section{TOOLS AND TECHNIQUE:}

There are several influential modern developments.

The atomic force microscope (AFM)

$>$ The Scanning Tunneling Microscope (STM) are scanning probes that launched nanotechnology [6].

Varity of assorted techniques of nanolithography such as:

Optical lithography.

X-ray lithography,

$>$ Dip pen nanolithography

\section{Electron beam lithography(inkjet printer)}

Were also developed.

Lithography in MEMS theme is typically the relocation of a pattern into a photosensitive material by selective exposure to a radiation source such as light.

Why the properties of material/structure are different at nanoscale?

$>$ Ratio of surface area to volume structure will be increasing (most atom are at or close to the surface which make them more poorly bonded and more reactive)

$>$ Quantum mechanical effect are significant (size and structure on the same scale as the wavelength of electron and quantum confinement occurs resulting in reshape of electronic and optical property).

CARBON NANOTUBES ARE 20TIMES STRONGER THAN STEEL. 
International Journal of Trend in Scientific Research and Development (IJTSRD) ISSN: 2456-6470

\section{FUTURE:}

$>$ Nanotechnology may make it possible to manufacture flimsier, strudy, and programmable materials that entails less energy to produce than conventional material and that promise extraordinary fuel efficiency in land transportation, ships, aircraft, and space vehicles.

$>$ The future of nanotechnology could very well comprises the use of nanorobotics.

$>$ These nanorobots have the latent to take on human tasks as well as tasks that humans could never complete. The rebuilding of the depleted ozone layer could potentially be able to be accomplished. There would be an purenano surgical field to help cure everything from natural aging to diabetes to bone spurs.

$>$ There would be almost nothing, that couldn't be patched up(eventually) with the establishment of nano surgery.

\section{DRAW BACK:}

$>$ Nano-particles can get into the body through the skin, lungs and digestive system, thus generating free radicals that can engender of cell damage.

$>$ Once nano-particles are in the bloodstream, they will be able to cross the blood-brain barrier[7].

$>$ The most menacing Nano-application used for military purposes is the Nano-bomb that contain engineered self multiplying deadly viruses that can persist in wiping out a community, country or even a civilization.

$>$ Nanobots because of their replicating behavior can be big threat for GRAY GOO [8].

\section{CONCLUSION:}

Nanotechnology is an innovative technology that has just started; it is an anarchistic science that will shift all what we recognized before. This innovative technology will help us to keep ourselves healthy, because of nano-robots which repair the damage in our body. The other advantage is that it helps the scientist to analyze the atoms in the substance and make them smaller, lighter but yet a stonger substance to be used in future, just with the help of carbon nanotubes that are known to be a hundred times stronger than steel, in addition to that it is flexible too. With this new technology it is much more easy to convert energy, for instance the windmill that is being created with nano-technology blades are much more efficient in converting energy than the ordinary ones existing now. Now nano-technology covers almost all the field of science so as to bring a betterment in all prospective. It is expected that nano-technology will cover a lot more domains in further for the effective living on earth. Further the invension will be covered in the field of nano-science so as to make for lives better and easy. It is expected to have stunning results in future.

\section{REFERENCE}

1. https://books.google.co.in/books?id=KqHvAwAA QBAJ\&pg=PA3\&lpg=PA3\&dq=\%22The+term+ $\% 22$ nano-

technology $\% 22+$ was+first+used+by+Norio+Tanig uchi+in+1974,+though+it+was+not+widely+kno wn. $\% 22 \&$ source $=$ bl\&ots $=4$ WT5MumDTc \&sig $=$ g 1aOAy9dXjC8LcCSRruEZRxhfE4\&hl=en\&sa=X \&ved=2ahUKEwj7q5Hw6NbdAhUKY48KHauC ByYQ6AEwCnoECAkQAQ\#v=onepage $\& q=\% 22$ The $\% 20$ term $\% 20 \% 22$ nanotechnology $\% 22 \% 20$ was $\% 20$ first $\% 20$ used $\% 20$ by \%20Norio\%20Taniguchi\%20in\%201974\%2C\%20 though $\% 20$ it $\% 20$ was $\% 20$ not $\% 20$ widely $\% 20 \mathrm{know}$ n. $\% 22 \& \mathrm{f}=$ false

2. https://www.nanotechnologyworld.org/what-isnanotechnology

\section{3. http://www.uap-}

bd.edu/Press\&media/Concepts_of_Nanotechnolog y_of_pro_dr_sultanmahmud.html

4. https://www.coursehero.com/file/p1qeuad/nanotec hnology-refers-to-the-projected-ability-toconstruct-items-from-the/

5. https://www.slideshare.net/kirtisingh2011/nanotec hnology-ppt

6. http://www.academia.edu/11082984/Nano_Electr o_Mechanical_System

7. https://www.civilserviceindia.com/subject/General -Studies/notes/awareness-in-the-fields-of-nanotechnology.html

8. https://medcraveonline.com/JACCOA/JACCOA02-00053.php 